\title{
Pharmacotherapy for weight loss in adults with type 2 diabetes: a systematic review of randomised controlled trials
}

\author{
CLAUDIA COELHO, ${ }^{1}$ RACHEL AGIUS, ${ }^{2}$ JAMES CRANE, ${ }^{1}$ BARBARA MCGOWAN ${ }^{1,3}$
}

\begin{abstract}
Background: Clinically significant weight loss improves glycaemic control and cardiovascular disease risk in patients with type 2 diabetes (T2DM).

Aim: To identify and assess the efficacy of medical treatments for weight loss in adults with T2DM.

Methods: A systematic review was conducted of peerreviewed literature between July 2004 and July 2020 via PubMed, Embase, Web of Science, medRxiv and Cochrane Central Register of Controlled Trials. Randomised controlled trials (RCTs) in English investigating medical treatments for weight loss in patients with T2DM were included. RCTs of pharmacotherapy withdrawn from the market were excluded. No minimum length of follow-up time was established. Outcomes of interest were changes from baseline in body weight (\%), changes from baseline in $\mathrm{HbA}_{1 \mathrm{c}}(\%$, $\mathrm{mmol} / \mathrm{mol}$ ) and proportion of patients who achieved $\geq 5 \%$ weight loss. Quality assessment was evaluated using the Jadad score.

Results: Fifteen RCTs were included with a total of 4,207 participants with T2DM. Interventions included medications approved for obesity management (orlistat, liraglutide, naltrexone-bupropion and phentermine-topiramate) and other agents investigated for the primary purpose of weight loss (topiramate, metreleptin, dapagliflozin and exenatide) compared with placebo. The duration of the intervention varied from 12 to 56 weeks. Placebo-adjusted body weight loss ranged from $2.2 \%$ to $7.3 \%$. Furthermore, $30.5-77.0 \%$ of patients achieved $\geq 5 \%$ weight loss. Placebo-adjusted change in glycated haemoglobin was $0.3-1.5 \%(3.3-16.4 \mathrm{mmol} / \mathrm{mol})$. Conclusion: Current evidence demonstrates that pharmacotherapy for weight loss, except for leptin, is associated with weight loss and glycaemic improvement in patients with T2DM.
\end{abstract}

Br J Diabetes 2021;21:20-29

Guy's and St Thomas' NHS Foundation Trust, London, UK

Diabetes and Endocrine Centre, Mater Dei Hospital, Msida, Malta

King's College London - Diabetes and Nutritional Sciences, London, UK

Address for correspondence: Professor Barbara McGowan Department of Diabetes and Endocrinology, 3rd Floor Southwark Wing, Guy's Hospital, Great Maze Pond, London SE1 9RT

E-mail: Barbara.McGowan@gstt.nhs.uk

https://doi.org/10.15277/bjd.2021.281
Key words: obesity, pharmacotherapy, type 2 diabetes, weight loss, systematic review

\section{Background}

Obesity is known to be one of the major drivers for the onset of type 2 diabetes (T2DM). In tandem with the worldwide surge in the prevalence of obesity, a parallel rise in the prevalence of T2DM has also been observed over the past decade, making it one of the most common metabolic conditions worldwide. ${ }^{1,2}$ Although lifestyle modification remains the mainstay of all obesity treatment strategies, obesity pharmacotherapy can be a safe and effective adjunct to lifestyle modification. ${ }^{3-5}$ To date, only seven drugs have been available for obesity treatment and three (sibutramine, rimonabant and lorcaserin) have been subsequently withdrawn for safety concerns. With the exception of orlistat available since 1998, remaining therapies have only recently become available within the last decade. ${ }^{6}$ This systematic review aims to summarise the efficacy of available pharmacotherapies in the setting of randomised clinical research trials, as well as those pharmacotherapies licensed for other indications subjected to randomised trial investigation for weight loss.

The aim of this study is to review systematically the evidence available and assess changes from baseline in body weight (\%) for pharmacotherapy treatments for weight loss in patients with T2DM in comparison with placebo.

\section{Methods}

The review was conducted according to the Preferred Reporting Items for Systematic Reviews and Meta-Analyses (PRISMA) statement. The methodology of the analysis and inclusion criteria were pre-specified in advance and documented in a protocol (see Appendix 1 available online www.bjd-abcd.com).

\section{Eligibility criteria}

The review included randomised controlled trials (RCTs) investigating pharmacotherapy for weight loss from peer-reviewed literature published in English since July 2004. The last systematic review on this topic conducted a search until June 2004. Participants were adult patients with T2DM. The intervention was defined as medical treatments with the primary objective of weight loss compared with placebo. This included pharmacotherapy approved for obesity treatment per se and other agents investigated for weight loss. Weight loss strategies such as behavioural therapy could be used in conjunction with the intervention. No minimum 
length of follow-up time was established. Obesity pharmacotherapy used for shorter periods may offer an opportunity to bridge patients to other long-term treatments, or to achieve a targeted short-term weight loss goal (eg, in the run-up to orthopaedic surgery). Furthermore, the short-term duration response allows understanding on long-term pharmacotherapy maintenance. In clinical practice, if the patient is a non-responder (ie, does not lose at least $5 \%$ of body weight at 12 weeks maximum dose), treatment should be discontinued.

Pharmacotherapy withdrawn from the market due to safety concerns and non-regulated supplements were excluded from this review. Primary outcomes were defined as changes in body weight (\%) from baseline. Secondary outcomes were defined as changes from baseline in glycated haemoglobin $\left(\mathrm{HbA}_{1 \mathrm{c}}\right)(\%$, $\mathrm{mmol} / \mathrm{mol}$ ) and proportion of patients achieving $\geq 5 \%$ weight loss.

\section{Information sources and search strategy}

Electronic searches were performed of PubMed, Embase, Web of Science, Cochrane Central Register of Controlled Trials and medRxiv, supplemented with searches of reference lists and selected journals. The databases were searched from July 2004 to July 2020. The final search strategy for PubMed was performed as follows: (((("Weight Loss/drug therapy" [Mesh]) OR "Obesity/ drug therapy"[Mesh] OR "Anti-Obesity Agents"[Mesh]) OR "Overweight/drug therapy"[Mesh] OR "Appetite Depressants"[Mesh]) AND "Diabetes Mellitus, Type 2" [Mesh]. Filters: English, from 2004 to 2020 .

\section{Study selection and data collection process}

Titles and abstracts were reviewed for relevance by one author. If information in the abstracts was insufficient, two review authors retrieved and assessed potentially relevant full texts for inclusion. In cases of uncertainty, the other review author was consulted and consensus attained; if required, a third author was consulted. For all included studies, one review author extracted the data using a standardised template and a second author verified the extracted data for accuracy. Mean values of change from baseline in weight and $\mathrm{HbA}_{1 \mathrm{c}}$ during follow-up were extracted at the end of the intervention. All data reported as absolute values during follow-up were converted to change from baseline in unit percent by dividing by the baseline weight.

\section{Assessment of risk of bias}

The risk of bias was assessed by the Jadad score including appropriate method for randomisation, adequate blinding and detailed report of withdrawals. ${ }^{7}$ The Jadad score was used for descriptive purposes and not for study selection.

\section{Results}

\section{Study selection}

The PRISMA flow diagram is shown in Figure 1.

\section{Study characteristics}

Fifteen RCTs met our inclusion criteria with a total of 4,207 participants. The studies reported on eight different agents investigated for weight loss, four agents approved by the Food and Drug Administration and/or European Medicines Agent (EMA) for obesity treatment (orlistat, liraglutide, naltrexone-bupropion and phentermine-topiramate) and four others investigated for the primary purpose of weight loss (topiramate, metreleptin, dapagliflozin and exenatide). Orlistat, liraglutide and naltrexone-bupropion are approved by the EMA and are available in the UK; however, only orlistat is readily accessible in the National Health Service (NHS). More recently, the National Institute for Health and Care Excellence (NICE) has approved the use of liraglutide $3 \mathrm{mg}\left(\right.$ Saxenda $\left.{ }^{\circledR}\right)$ in the English and Welsh NHS for patients with a body mass index $>35 \mathrm{~kg} / \mathrm{m}^{2}$, pre-diabetes, increased cardiovascular risk and referred to a Tier 3 structured weight loss programme. Four trials were multinational, nine studies were multicentric based in one country and two studies were single-centre. The year of publication ranged from 2004 to 2020. In terms of T2DM background medication, three studies included patients treated solely with diet, in four studies participants were only taking metformin and in seven studies participants were on multiple glucose-lowering agents. Thirteen studies excluded patients on insulin, whilst one study specifically enrolled patients on basal insulin. All studies were randomised, double-blinded, placebocontrolled and parallel assignment. Participants were randomised to weight loss medication versus placebo. In all studies, with one exception, participants were placed on adjunctive lifestyle interventions, which included calorie restriction and increased physical activity recommendations. Fourteen studies reported on change in $\mathrm{HbA}_{1 \mathrm{c}}$ and 10 studies informed on the proportion of patients achieving $\geq 5 \%$ body weight loss. Outcome measures were assessed at the end of the intervention, which varied from 12 to 56 weeks.

Table 1 Quality assessment of eligible randomised controlled trials using the Jadad score to assess methodological quality of controlled clinical trials (including appropriateness of randomisation, adequate blinding and reports of withdrawals)

\begin{tabular}{|c|c|c|c|c|}
\hline Study & $\begin{array}{l}\text { Adequate } \\
\text { sequence } \\
\text { generation }\end{array}$ & $\begin{array}{l}\text { Allocation } \\
\text { concealment }\end{array}$ & $\begin{array}{l}\text { Blinding of } \\
\text { participants } \\
\text { and } \\
\text { personnel }\end{array}$ & $\begin{array}{l}\text { Dropout } \\
\text { addressed }\end{array}$ \\
\hline Apovian, $2010^{17}$ & Adequate & Adequate & Adequate & Adequate \\
\hline Berne, $2005^{8}$ & Adequate & Adequate & Adequate & Adequate \\
\hline Bolinder, $2012^{18}$ & Adequate & Adequate & Adequate & Adequate \\
\hline Davies, $2015^{13}$ & Adequate & Adequate & Adequate & Adequate \\
\hline Derosa, $2012^{10}$ & Adequate & Adequate & Adequate & Adequate \\
\hline Gadde, $2011^{16}$ & Adequate & Adequate & Adequate & Adequate \\
\hline Garvey, $2020^{14}$ & Adequate & Adequate & Adequate & Adequate \\
\hline Guy-Grande, $2004^{11}$ & Adequate & Adequate & Adequate. & Adequate \\
\hline Hollander, $2013^{15}$ & Adequate & Adequate & Adequate & Adequate \\
\hline Kuo, $2006^{9}$ & Adequate & Not reported & Adequate & $\begin{array}{l}\text { Not } \\
\text { reported }\end{array}$ \\
\hline Moon, $2011^{19}$ & Adequate & Not reported & Adequate & $\begin{array}{l}\text { Not } \\
\text { reported }\end{array}$ \\
\hline Rosenstock, $2007^{22}$ & Adequate & Adequate & Adequate & Adequate \\
\hline Shi, $2005^{12}$ & Adequate & Not reported & Adequate & Adequate \\
\hline Stenlöf, $2007^{20}$ & Adequate & Not reported & Adequate & Adequate \\
\hline Toplak, $2007^{21}$ & Adequate & Adequate & Adequate & Adequate \\
\hline
\end{tabular}


Figure 1. Study selection flowchart. The search retrieved a total of 5,528 articles. After removing duplicates and reviewing abstracts, 109 full-text articles were examined in detail for eligibility. Studies eligible were RCTs investigating drugs for weight loss in adults with T2DM and whose primary outcome was defined as changes in body weight (\%) from baseline. Fifteen RCTs met the eligibility criteria and were included in the review.

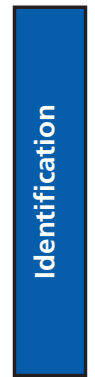

Records identified through database searching:

PubMed $(n=2,056)$

EMBASE $(n=1,539)$

Web of Science $(n=1,532)$

Cochrane Central Register of

Controlled Trials $(n=346)$

MedRxiv $(n=41)$
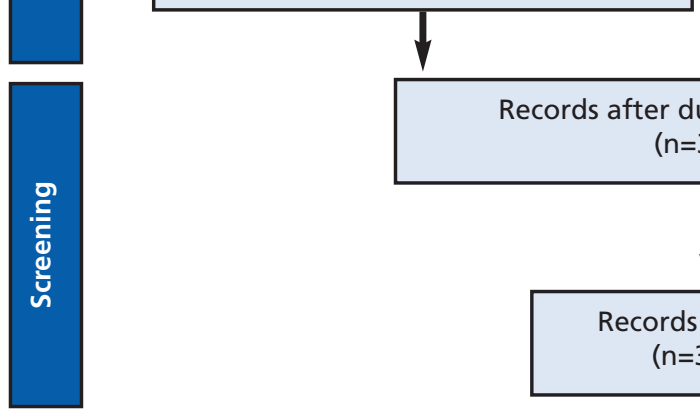

Records after duplicates removed $(n=3,190)$
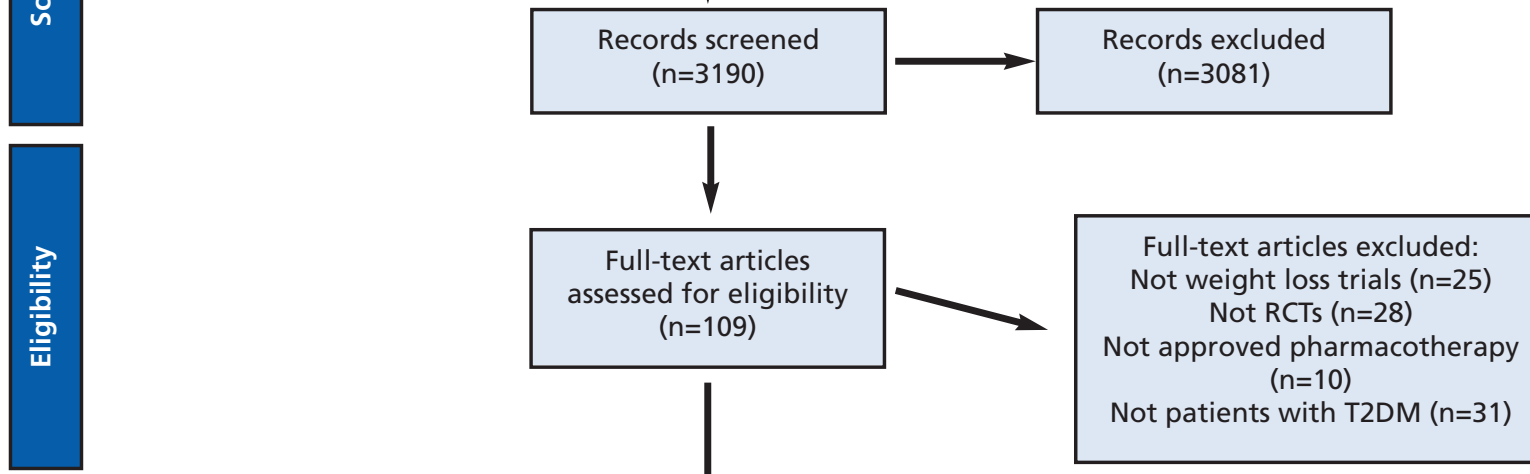

Records excluded $(n=3081)$

Studies included in

qualitative synthesis $(n=15)$

One study reported on weight 12 weeks after treatment discontinuation. Quality assessment evaluated by the Jadad score is shown in Table 1 and study characteristics are shown in Table 2. Outcomes in body weight loss (\%), changes from baseline in $\mathrm{HbA}_{1 \mathrm{c}}$ ( $\mathrm{mmol}$ / mol) and proportion of patients who achieved $\geq 5 \%$ weight loss are presented in Figures 2, 3 and 4, respectively.

\section{Pharmacotherapy approved for weight loss}

\section{Orlistat}

Five RCTs investigated orlistat, ${ }^{8-12}$ comprising a total of 976 patients. Sample size varied from 60 to 254 participants and study duration ranged from 12 to 52 weeks. The majority of patients were on metformin and sulfonylurea, a smaller subset of participants were tak- ing insulin ( $n=14)$. All studies demonstrated significant body weight loss from baseline with orlistat, ranging from 3.3\% at 12 weeks to $10.1 \%$ at 52 weeks. Furthermore, reduction in $\mathrm{HbA}_{1 \mathrm{c}}$ of $0.5 \%$ (5.5 $\mathrm{mmol} / \mathrm{mol})$ at 24 weeks to $1.7 \%(18.6 \mathrm{mmol} / \mathrm{mol})$ at 12 weeks was noted with orlistat versus $0.2 \%(2.2 \mathrm{mmol} / \mathrm{mol})$ to $0.6 \%(6.6$ $\mathrm{mmol} / \mathrm{mol}$ ) with placebo. At the end of the trial, in comparison to placebo, all studies found a significant body weight and $\mathrm{HbA}_{1 \mathrm{c}}$ reduction, except for one trial in which no differences were found in glycaemic control. ${ }^{10}$ Two trials reported on the proportion of patients who achieved more than $5 \%$ body weight loss, 35.1$45.9 \%$ of patients assigned to orlistat versus $7.3-10.9 \%$ of those taking placebo. The discontinuation rate of the study drug was stated in three trials and varied from $6.4 \%$ to $13.5 \%$ for patients in the orlistat arm and from $4.0 \%$ to $13.8 \%$ in the placebo group. 
Table 2 Study characteristics of eligible RCTSs included in this systematic review (between 2004 and 2020) investigating pharmacotherapy for weight loss in adult patients with T2DM

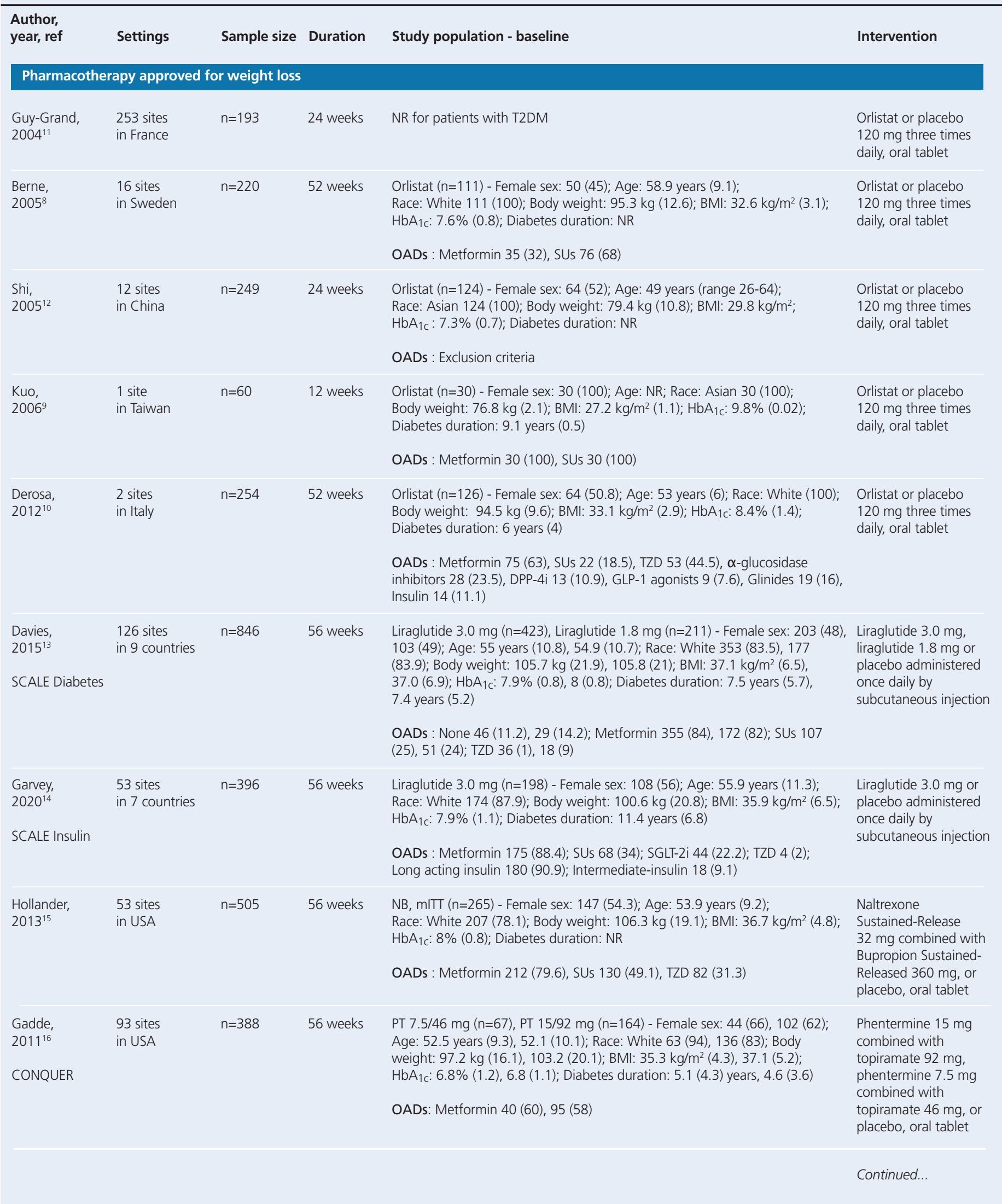


Table 2 Continued

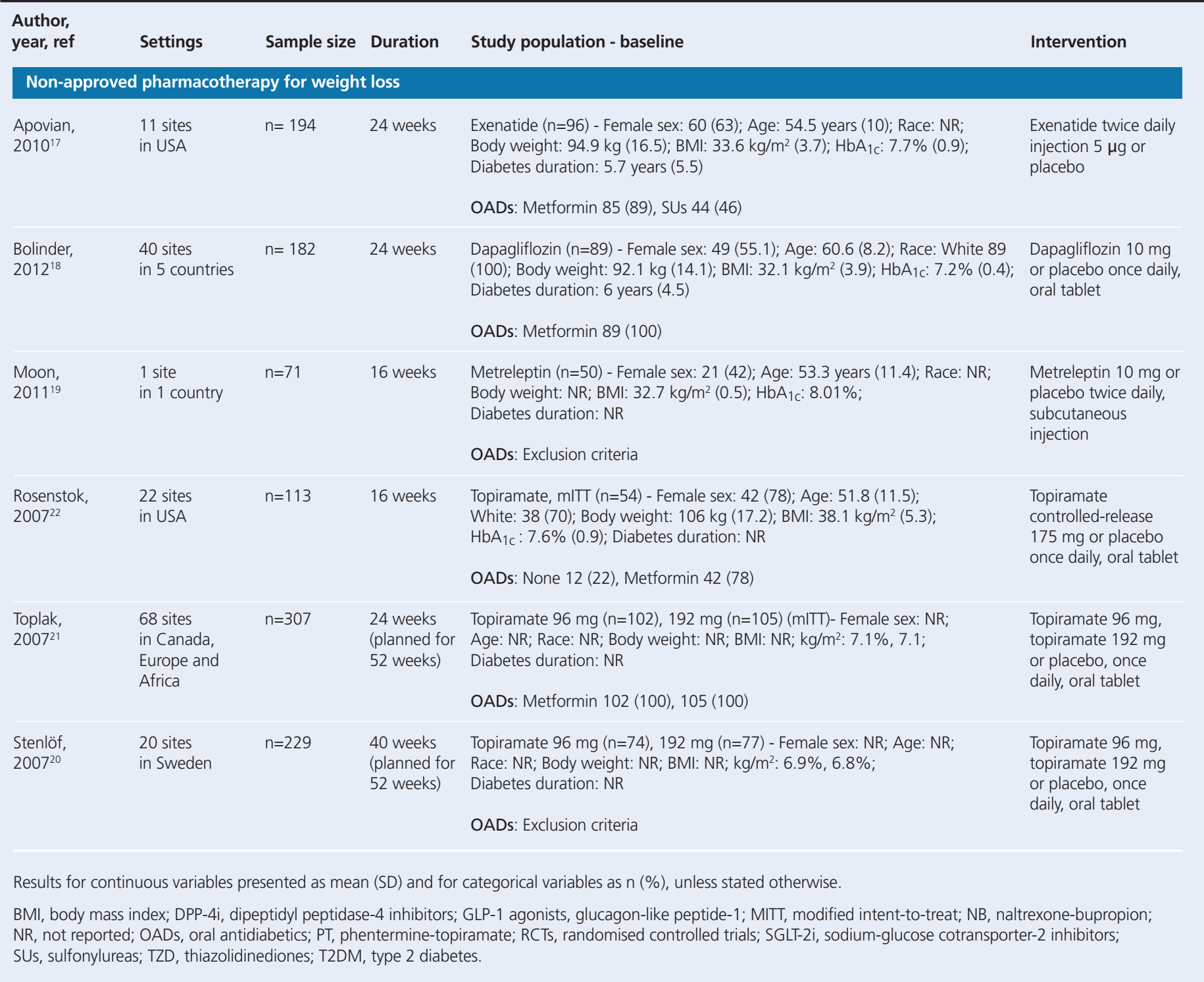

\section{Liraglutide}

Two RCTs evaluated the efficacy of liraglutide $3.0 \mathrm{mg}$ on weight loss in patients with T2DM, with a total of 1,242 participants. The SCALE Diabetes trial with liraglutide $3.0 \mathrm{mg}$ and $1.8 \mathrm{mg}$ excluded patients medicated with insulin, ${ }^{13}$ whereas the SCALE Insulin trial recruited exclusively patients taking insulin. ${ }^{14}$ Both trials lasted 56 weeks, which included a 4-week titration phase. Additionally, SCALE Diabetes had a 12-week observational follow-up period after drug discontinuation. In SCALE Diabetes, the weight reduction was $6.0 \%, 4.7 \%$ and $2.0 \%$ with an associated $\mathrm{HbA}_{1 \mathrm{c}}$ reduction of $1.3 \%(14.2 \mathrm{mmol} / \mathrm{mol}), 1.1 \%(12 \mathrm{mmol} / \mathrm{mol})$ and $0.3 \%(3.3$ $\mathrm{mmol} / \mathrm{mol}$ ) in the liraglutide $3.0 \mathrm{mg}, 1.8 \mathrm{mg}$ and placebo arms, respectively. The 12-week follow-up evidenced weight regain. In SCALE Insulin, the patients who were assigned to liraglutide 3.0 mg lost $5.8 \%$ of their baseline body weight compared with $1.5 \%$ in participants taking placebo. In terms of metabolic control, $\mathrm{HbA}_{1 \mathrm{c}}$ decreased by $1.1 \%(12 \mathrm{mmol} / \mathrm{mol})$ in the liraglutide group and
$0.6 \%(6.6 \mathrm{mmol} / \mathrm{mol})$ in the placebo-treated group. Furthermore, 21 participants on liraglutide (versus three participants on placebo) were able to discontinue insulin. In both trials, more than half of the patients achieved $\geq 5 \%$ weight loss on liraglutide $3.0 \mathrm{mg}$. In SCALE Diabetes, $23.4 \%$ participants in the liraglutide $3.0 \mathrm{mg}$ arm discontinued the study drug compared with $33.9 \%$ in the placebo arm versus $16.2 \%$ and $15.2 \%$ of participants in the liraglutide and placebo arms, respectively, in SCALE Insulin.

\section{Naltrexone-bupropion}

In a 56-week trial of naltrexone-bupropion, 505 participants were randomised to naltrexone-bupropion or placebo in a 2:1 ratio. ${ }^{15}$ The investigational medicinal product was taken as a single tablet containing $8 \mathrm{mg}$ naltrexone sustained release (SR) combined with $90 \mathrm{mg}$ bupropion SR, or placebo. The dose was titrated over 4 weeks to a maintenance dose of $32 \mathrm{mg}$ naltrexone SR and $360 \mathrm{mg}$ bupropion SR, taken as 4 tablets daily. Patients assigned to naltrex- 
Figure 2. Effect of weight loss pharmacotherapy versus placebo on body weight reduction (\%) from baseline to follow-up. In all studies, participants were on adjunctive lifestyle interventions. The RCTs were grouped by weight loss agent. Weight loss was assessed at the end of the intervention, ranging from 12 to 56 weeks.

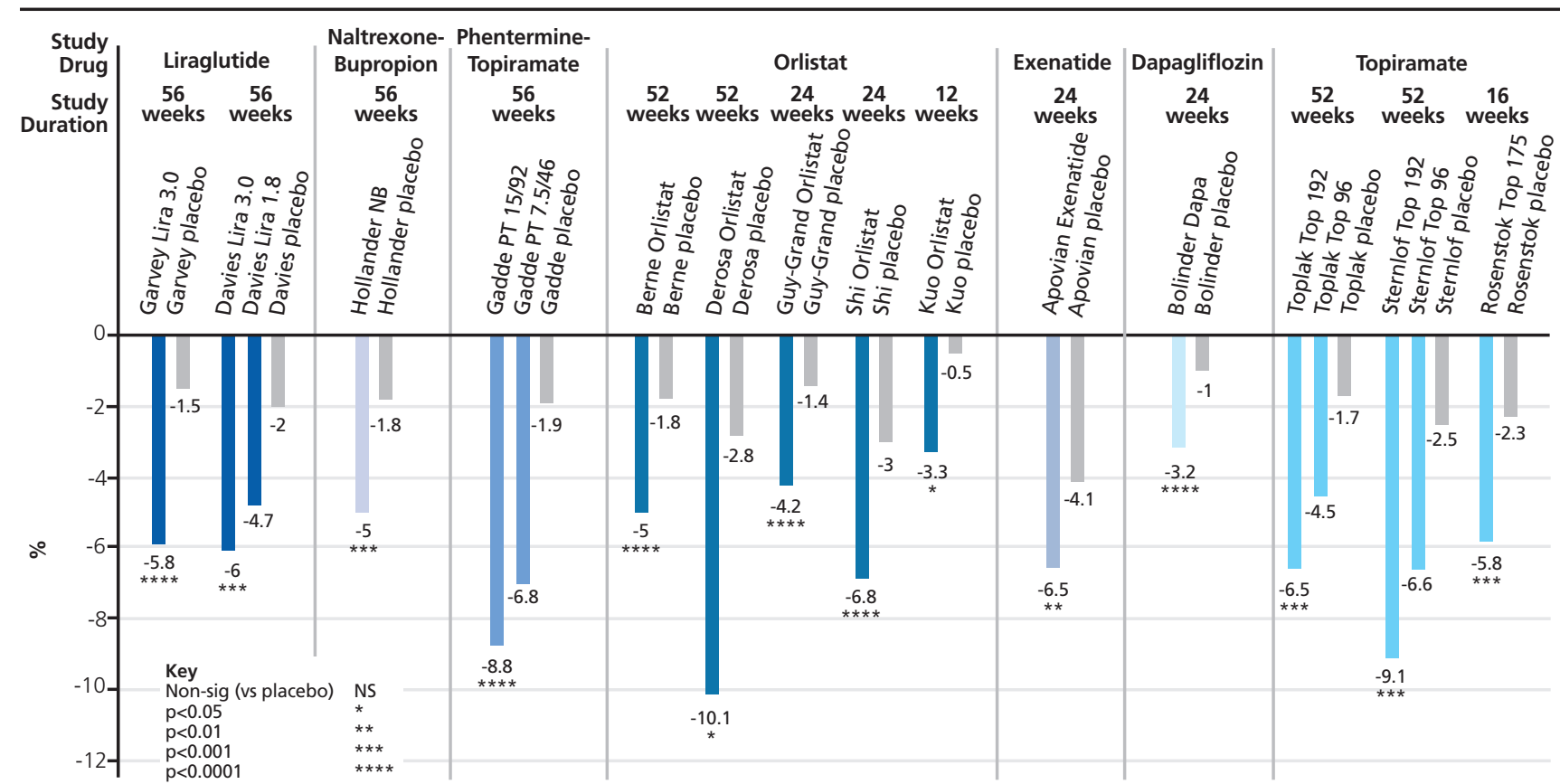

RCTs, randomised controlled trials

Figure 3. Effect of weight loss pharmacotherapy versus placebo on $\mathrm{HbA} 1 \mathrm{c}(\mathrm{mmol} / \mathrm{mol})$ from baseline to follow-up. In all studies, participants were on adjunctive lifestyle interventions. The RCTs were grouped by weight loss agent. Weight loss was assessed at the end of the intervention, ranging from 12 to 56 weeks.

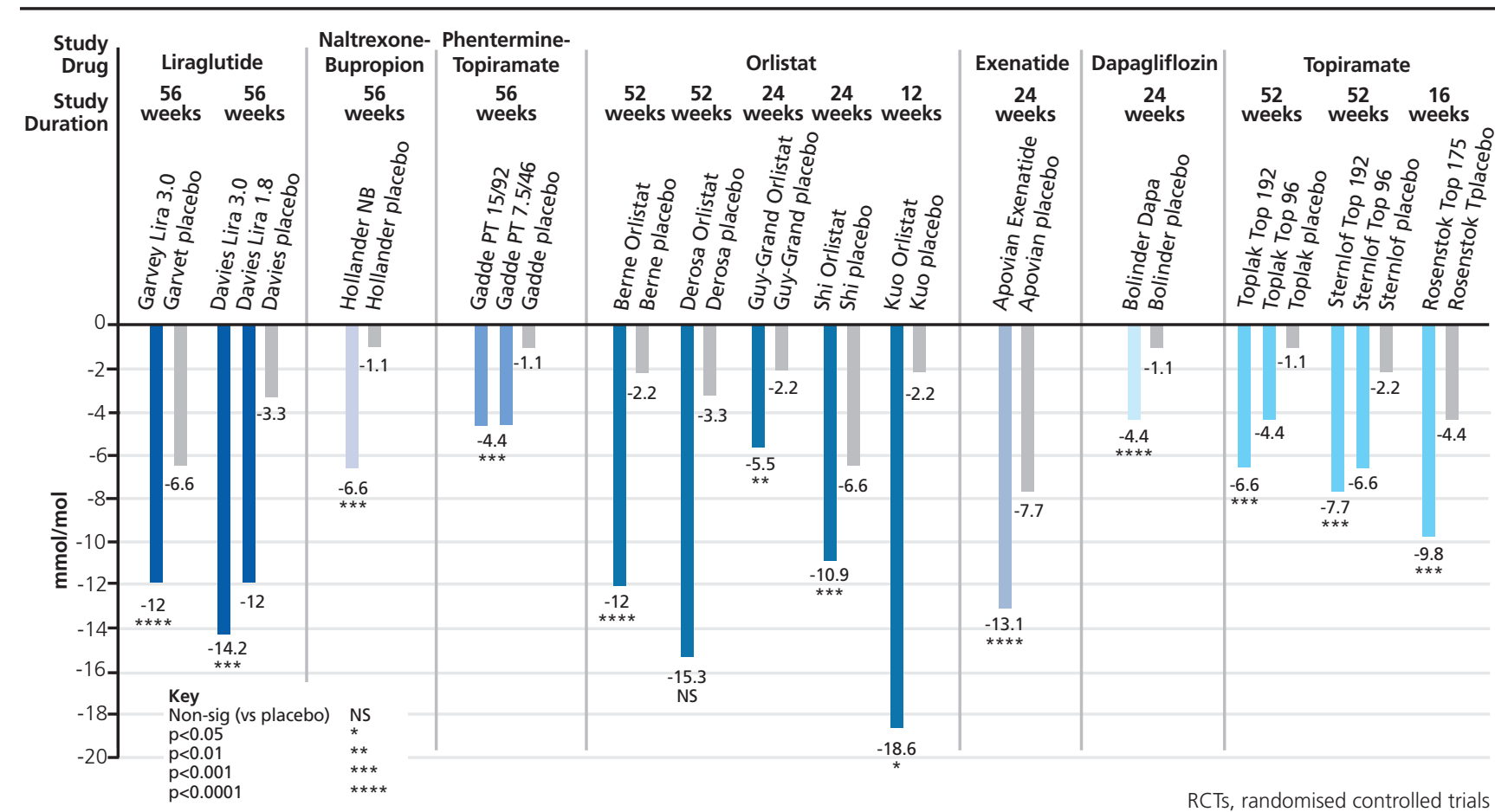


Figure 4. Impact of weight loss agents versus placebo on proportion of individuals who lost $\geq 5 \%$ of their baseline body weight. Each bar (different shades of blue for pharmacotherapy and grey for placebo) represents the proportion of participants in the trial who achieved $\geq 5 \%$ body weight loss. RCTs, randomised controlled trials.

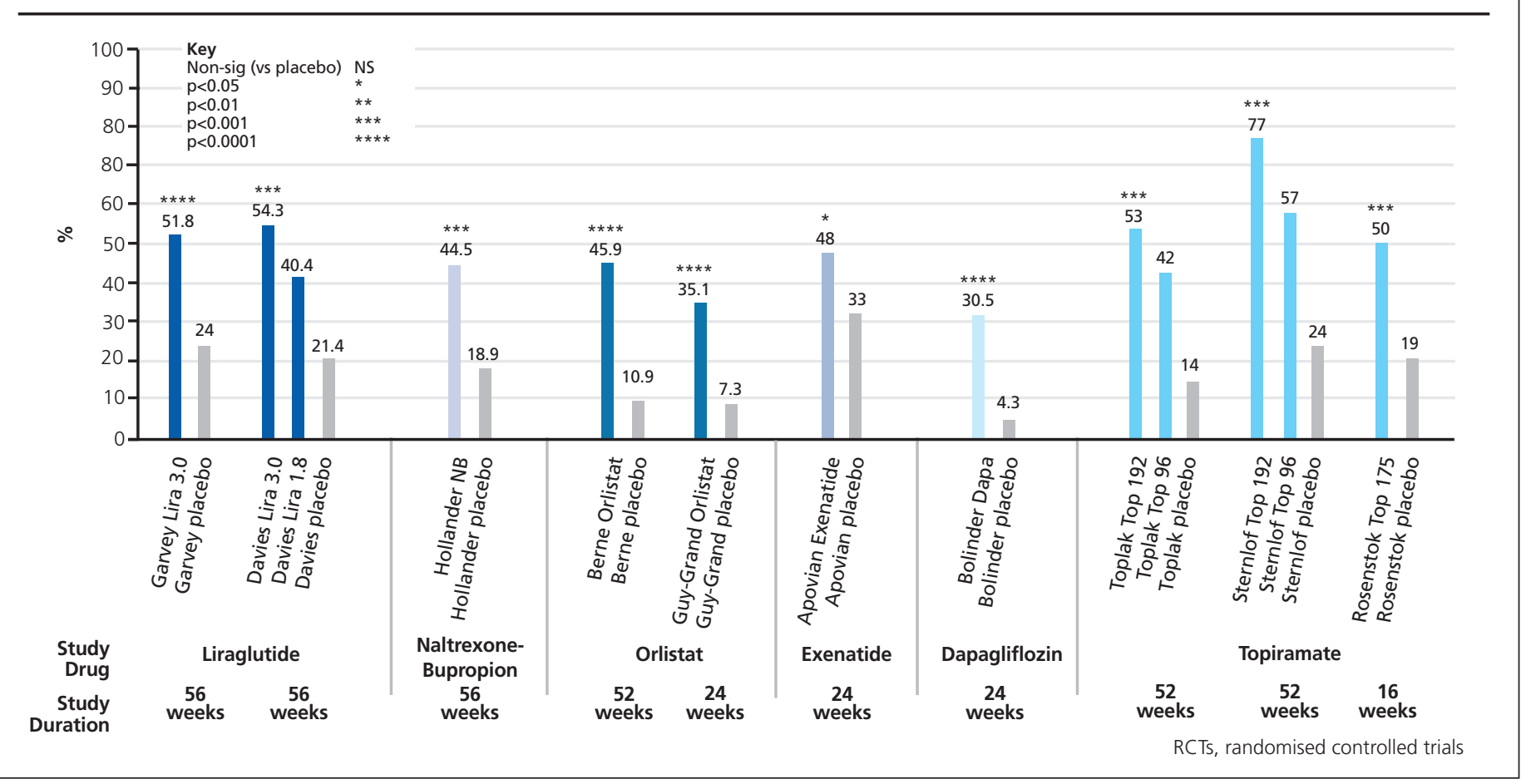

one-bupropion had a $5.0 \%$ reduction in their baseline body weight compared with $1.8 \%$ in patients on placebo. Moreover, $\mathrm{HbA}_{1 \mathrm{c}}$ dropped by $0.6 \%(6.6 \mathrm{mmol} / \mathrm{mol})$ in patients taking naltrexonebupropion versus $0.1 \%(1.1 \mathrm{mmol} / \mathrm{mol})$ in patients allocated to placebo. More than double the patients assigned to naltrexonebupropion lost at least 5\% of their initial body weight compared with those on placebo (44.5\% versus 18.9\%). Over the trial period, $160(47.8 \%)$ participants in the naltrexone-bupropion group discontinued the study drug compared with 70 (41.2\%) participants in the placebo group. Efficacy analyses were performed using the modified intent-to-treat and last observation carried forward.

\section{Phentermine-topiramate}

In CONQUER, a 56-week trial, 2,487 patients with two or more weight-related complications were randomised to either phentermine-topiramate at two different doses or placebo. ${ }^{16}$ The 388 participants who had T2DM were included in the review. Patients randomised to phentermine $15 \mathrm{mg}$ plus topiramate $92 \mathrm{mg}$ (PT $15 / 92 \mathrm{mg}$ ) or phentermine $7.5 \mathrm{mg}$ plus topiramate $46 \mathrm{mg}$ (PT $7.5 / 46 \mathrm{mg}$ ) lost $8.8 \%$ and $6.8 \%$ of their baseline body weight, respectively, compared with $1.9 \%$ in patients in the placebo group. Patients assigned to both doses of phentermine-topiramate showed $\mathrm{HbA}_{1 \mathrm{c}}$ improvements of $0.4 \%$ (4.4 mmol/mol) compared with $0.1 \%(1.1 \mathrm{mmol} / \mathrm{mol})$ in the placebo group. The proportion of patients who achieved $\geq 5 \%$ of weight loss was not reported. There was a $24.4 \%$ and $22.4 \%$ drug discontinuation rate for PT 15/92 mg and PT 7.5/46 mg, respectively, in comparison to $28.0 \%$ for placebo.

\section{Non-approved pharmacotherapy for weight loss}

\section{Exenatide}

Exenatide is an injectable incretin mimetic used for T2DM treatment. One RCT studied the effect of a lifestyle modification programme plus exenatide $5 \mu \mathrm{g}$ twice daily injection on weight loss in 194 patients with T2DM medicated with metformin or sulfonylurea. ${ }^{17}$ At 24 weeks, participants on exenatide had a $6.5 \%$ body weight reduction compared with $4.1 \%$ in patients on placebo. The $\mathrm{HbA}_{1 \mathrm{c}}$ change was $1.2 \%(13.1 \mathrm{mmol} / \mathrm{mol})$ for participants taking exenatide versus $0.7 \%(7.7 \mathrm{mmol} / \mathrm{mol})$ for placebo. Half of the participants taking exenatide achieved $\geq 5 \%$ weight loss compared with one-third of patients assigned to placebo. The discontinuation rate was $26.8 \%$ in the exenatide group and $26.2 \%$ in the placebo group.

\section{Dapagliflozin}

Dapagliflozin is a sodium-glucose co-transporter-2 (SGLT-2) inhibitor approved for T2DM treatment. In a 24-week trial of dapagliflozin with 182 participants the authors aimed to confirm weight loss and determine if body weight reduction was due to fat or fluid component changes. ${ }^{18}$ Participants who were treated with dapagliflozin $10 \mathrm{mg}$ lost $3.2 \%$ of their initial body weight and had an $\mathrm{HbA}_{1 \mathrm{c}}$ reduction of $0.4 \%(4.4 \mathrm{mmol} / \mathrm{mol})$ compared with a $1.0 \%$ weight loss and $0.1 \%(1.1 \mathrm{mmol} / \mathrm{mol}) \mathrm{HbA}_{1 \mathrm{c}}$ reduction in the placebo group. With dapagliflozin, $30.5 \%$ of individuals achieved $\geq 5 \%$ weight loss versus $4.3 \%$ with placebo. Additionally, body composition measurements demonstrated that the weight loss associated 
with dapagliflozin was mainly due to reductions in fat mass, assessed by dual-energy $x$-ray absorptiometry (DEXA). In order to allow DEXA measurements, patients with body weight above $120 \mathrm{~kg}$ were excluded. Furthermore, a low baseline $\mathrm{HbA}_{1 \mathrm{c}}$ was deliberately chosen by the investigators to ensure patients did not withdraw from the study due to suboptimally controlled T2DM. The discontinuation rate was $8.8 \%$ for dapagliflozin and $5.5 \%$ in the placebo group.

\section{Leptin}

Metreleptin is indicated as replacement therapy for the complications of leptin deficiency in patients with lipodystrophy. It is administered by subcutaneous injection. One RCT investigated leptin for the primary purpose of weight loss in 71 participants for 16 weeks. ${ }^{19}$ Furthermore, the study aimed to assess immune responses to metreleptin and detail on mechanisms underlying leptin resistance. Patients on glucose lowering agents were excluded. Concomitant lifestyle measures were not reported. The study showed that there were no significant weight changes with this agent in comparison to placebo at 16 weeks. Furthermore, no changes in circulating inflammatory markers were noted. Glycaemic control slightly improved compared with baseline in patients assigned to leptin; $\mathrm{HbA}_{1 \mathrm{c}}$ was reduced from $8.01 \%(64 \mathrm{mmol} / \mathrm{mol})$ to $7.96 \%(63.5$ $\mathrm{mmol} / \mathrm{mol})(p=0.03)$. No data were available on glycaemic parameters in the placebo group.

\section{Topiramate}

Three RCTs investigated topiramate for weight loss, including a total of 649 participants. ${ }^{19-21}$ The formulations were $192 \mathrm{mg}, 175 \mathrm{mg}$ and $96 \mathrm{mg} /$ day. In two trials there was a 6-week single-blind placebo run-in. In all trials there was a 7-8-week titration period. Patients were recently diagnosed with T2DM and drug-naïve, or solely on metformin. Two trials were interrupted early due to the sponsor's decision to pursue other formulations to improve tolerability and simplify dosage..$^{20,21}$ In a brought forward and intent-to-treat analysis performed at 24 weeks with 307 patients medicated with metformin for T2DM, topiramate showed significant body weight reduction (6.5\% for topiramate $192 \mathrm{mg}, 4.5 \%$ for topiramate $96 \mathrm{mg}$ ) and $\mathrm{HbA}_{1 \mathrm{c}}$ improvement $(0.6 \%(6.6 \mathrm{mmol} / \mathrm{mol})$ for topiramate 192 $\mathrm{mg}, 0.4 \%(4.4 \mathrm{mmol} / \mathrm{mol})$ for topiramate $96 \mathrm{mg})$ compared with the control group $(1.7 \%$ body weight reduction, $0.1 \%(1.1$ $\mathrm{mmol} / \mathrm{mol}$ ) $\mathrm{HbA}_{1 \mathrm{c}}$ improvement). ${ }^{21}$ Moreover, in a brought forward and intent-to-treat analysis completed at 40 weeks with 229 patients naïve to glucose-lowering drug treatment, topiramate significantly reduced body weight ( $9.1 \%$ for topiramate $192 \mathrm{mg}, 6.6 \%$ for topiramate $96 \mathrm{mg})$ and $\mathrm{HbA}_{1 \mathrm{c}}(0.7 \%(7.7 \mathrm{mmol} / \mathrm{mol})$ for topiramate $192,0.6 \%(6.6 \mathrm{mmol} / \mathrm{mol})$ for topiramate $96 \mathrm{mg})$ compared with the control group ( $2.5 \%$ weight loss, $0.2 \%(2.2 \mathrm{mmol} / \mathrm{mol})$ $\mathrm{HbA}_{1 \mathrm{c}}$ reduction). ${ }^{20}$ An $\mathrm{RCT}$ with topiramate $175 \mathrm{mg} /$ day for 16 weeks in 113 participants on metformin showed $5.8 \%$ baseline body weight loss in the topiramate arm compared with $2.3 \%$ in the placebo group and a placebo-adjusted $\mathrm{HbA}_{1 \mathrm{c}}$ improvement of $0.5 \%(5.5 \mathrm{mmol} / \mathrm{mol}){ }^{22}$ In all studies, the proportion of patients assigned to topiramate who achieved $\geq 5 \%$ body weight loss ranged from $42 \%$ with topiramate $96 \mathrm{mg}$ to $77.0 \%$ in individuals taking topiramate $192 \mathrm{mg} \cdot{ }^{19-21}$

\section{Discussion}

\section{Weight loss effects}

With the exception of leptin therapy, all pharmacotherapy agents investigated in this systematic review demonstrated significantly greater weight loss compared with placebo in patients with T2DM. The intensity of the lifestyle interventions in the clinical trials varied, so placebo-subtracted weight loss was used to compare weight loss attributable to pharmacological agents alone, which ranged from $2.2 \%$ to $7.3 \%$. For agents authorised for obesity treatment only, the weight loss was greatest for orlistat at $2.8-7.3 \%$ (but with significant variability), $6.9 \%$ for phentermine-topiramate $15 / 92 \mathrm{mg}$, $4.0-4.3 \%$ for liraglutide $3.0 \mathrm{mg}$ and $3.2 \%$ for naltrexone-bupropion $32 / 360 \mathrm{mg}$. Non-approved pharmacotherapy for weight loss achieved broadly similar weight reductions ranging from $2.2 \%$ to $6.6 \%$, with the greatest weight loss observed with topiramate at $2.8-6.6 \%, 2.4 \%$ for exenatide and $2.2 \%$ for dapagliflozin. Of note, these endpoints were measured on different time scales, which may have impacted the weight loss magnitude which tends to plateau at 6 months. ${ }^{3,23}$ Furthermore, baseline weight and background medication for T2DM varied across studies. The variable weight loss observed with orlistat may be explained by the fact that the lowest weight loss (2.8\%) was measured after 12 weeks of treatment, with maximum weight reduction unlikely to have been reached by that time point. Individuals assigned to topiramate $192 \mathrm{mg}$ showed a notable placebo-subtracted weight loss of $6.6 \%$, and $77 \%$ of participants achieved $>5 \%$ weight loss. All participants had been recently diagnosed with T2DM and were drug naïve, which may partly explain these results. Topiramate at a lower dose $(92 \mathrm{mg})$ is approved for weight loss in conjunction with phentermine $15 \mathrm{mg}$, as both drugs are used at lower doses with synergistic effect on weight loss, as shown by the significant body weight reduction of $6.9 \%$ in the CONQUER trial. ${ }^{16}$

This systematic review compares with a meta-analysis in 2004 involving 2,231 patients, ${ }^{24}$ which assessed weight loss outcomes from 14 RCTs using either fluoxetine, orlistat or sibutramine in individuals with T2DM. The meta-analysis concluded that, whilst all pharmacotherapies achieved statistically significant weight loss over a short-term period, more studies with a longer follow-up period were required to fully understand the effect of these drugs on weight and other health outcomes. ${ }^{24}$ Individuals with T2DM may be somewhat more disadvantaged when it comes to successful weight management. It has been consistently shown that patients with T2DM lose less weight with any treatment modality than those who do not have T2DM. ${ }^{3}$ The COR-I and COR-II trials with naltrexone-bupropion in patients without T2DM revealed a greater weight loss compared with COR-Diabetes of $4.8 \%$ and $5.2 \%$ versus $3.2 \%$, respectively. ${ }^{25,26}$ In the CONQUER trial with phentermine-topiramate, the subpopulation of patients with T2DM showed a weight reduction of $6.9 \%$ compared with the mean weight loss in all patients of 8.6\%. In SCALE Obesity with liraglutide, patients without T2DM lost $5.4 \%$ of their body weight compared with $4 \%$ in SCALE Diabetes. ${ }^{27}$ The reasons for these observations have not yet been fully elucidated but it is thought that the pathophysiological processes of T2DM itself may make weight loss more difficult to achieve. ${ }^{3}$ The use of certain glucose-lowering agents such as insulin, sulfonylureas 
and thiazolidinediones has been associated with weight gain. Furthermore, fear of hypoglycaemia and use of polypharmacy in the management of co-morbidities associated with T2DM may render behavioural modification more challenging. ${ }^{3,4,28-30}$ SCALE Diabetes evaluated weight changes after drug discontinuation and showed weight gain, highlighting the need to maintain anti-obesity therapy long term..$^{13}$ Several clinical trials with glucose-lowering agents have assessed weight loss as a secondary outcome. Clinical trial data suggest that SGLT-2 inhibitors and glucagon-like peptide-1 (GLP-1) receptor agonists produce a mean weight loss of approximately 2-3 $\mathrm{kg}$ in patients with T2DM. Despite their efficacy, there is considerable heterogeneity in their weight loss effect. ${ }^{31}$ The Semaglutide Treatment Effect in People with obesity (STEP trials $1-5$ ) aims to investigate the effect of semaglutide $2.4 \mathrm{mg}$ once weekly versus placebo on weight loss in adults with obesity. The STEP 2 trial specifically enrolled patients with T2DM. Results are expected to be published in 2021 and it is anticipated that semaglutide will be a new effective agent for weight loss. ${ }^{32}$

\section{Glycaemic effects}

For all but two of the studies (one with orlistat ${ }^{10}$ and the other with leptin ${ }^{19}$ ), significant glycaemic improvement was achieved with weight loss pharmacotherapy in comparison with placebo. The results of the systematic review showed a mean $\mathrm{HbA}_{1 c}$ corrected to placebo reduction of $0.3 \%(3.3 \mathrm{mmol} / \mathrm{mol})$ to $1.5 \%(16.4$ $\mathrm{mmol} / \mathrm{mol}$ ). The reduction in $\mathrm{HbA}_{1}$ yielded by glucose-lowering agents—namely, dapagliflozin and exenatide, $0.3 \%(3.3 \mathrm{mmol} / \mathrm{mol})$ and $0.5 \%(5.5 \mathrm{mmol} / \mathrm{mol})$, respectively — was aligned with the glycaemic improvements evidenced with pharmacotherapy approved for obesity: $0.5 \%$ ( $5.5 \mathrm{mmol} / \mathrm{mol}$ ) for naltrexone-bupropion, $0.3 \%$ (3.3 mmol/mol) for phentermine-topiramate, $0.3-1.5 \%$ (3.3-16.4 $\mathrm{mmol} / \mathrm{mol})$ for orlistat and $0.5-1 \%(5.5-10.9 \mathrm{mmol} / \mathrm{mol})$ for liraglutide $3.0 \mathrm{mg}$. The $\mathrm{HbA}_{1 \mathrm{c}}$ was measured at different timelines in patients on various T2DM treatment regimens, which may have impacted $\mathrm{HbA}_{1 \mathrm{c}}$ outcomes. Moreover, interpretation of $\mathrm{HbA}_{1 \mathrm{c}}$ should be interpreted with care due to the concomitant reduction in the number and dose of glucose-lowering agents observed in patients taking anti-obesity agents, which may lead to underestimation of glycaemic improvement. For instance, the difference in $\mathrm{HbA}_{1 \mathrm{c}}$ reduction with liraglutide $1.8 \mathrm{mg}$ and liraglutide $3.0 \mathrm{mg}$ in SCALE Diabetes was significant, albeit marginal at $0.2 \%(2.2 \mathrm{mmol} / \mathrm{mol})$; however, patients assigned to liraglutide $3.0 \mathrm{mg}$ demonstrated a greater decrease in use of glucose-lowering agents than those taking liraglutide $1.8 \mathrm{mg}(13.1 \%$ vs $8.3 \%)$. With orlistat, $\mathrm{HbA}_{1 \mathrm{c}}$ changes were beyond what would be expected with the magnitude of weight loss observed. The mechanism by which orlistat improves T2DM has been suggested to be partly weight-independent. ${ }^{33}$ Although weight reduction was more prominent with the higher dose of phentermine-topiramate, the change in $\mathrm{HbA}_{1 \mathrm{c}}$ was the same for both doses $(0.4 \%, 4.4 \mathrm{mmol} / \mathrm{mol})$. Importantly, only liraglutide (at the $1.8 \mathrm{mg}$ dose) and dapagliflozin have shown cardiovascular benefit in patients with T2DM. ${ }^{34,35}$ Cardiovascular outcome trials with naltrexone-bupropion were terminated prematurely twice due to early release of preliminary results and the sale of the drug rights to another pharmaceutical company. ${ }^{36}$

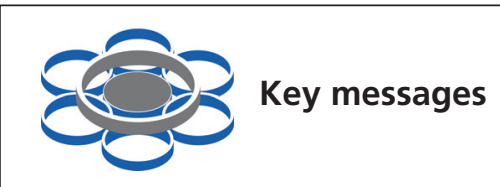

- Obesity is a driver for the onset of T2DM

- One of the major cornerstones for the management of individuals with T2DM and obesity is weight loss

- Obesity pharmacotherapy is proven to be a safe and effective adjunct to lifestyle modification in the management of patients living with obesity and T2DM

- All currently available agents for obesity management demonstrate greater weight loss and significant improvement in glycaemic control compared with placebo in individuals with T2DM

- Longer term clinical trials are required to fully assess the sustainability of weight loss, improvement in $\mathrm{HBA}_{1 c}$ and cardiovascular outcomes

\section{Limitations of the study}

The searches conducted only included studies in English. There is a relative paucity of data and study heterogeneity was not assessed. The evidence is also limited by lack of ethnic diversity as the majority of participants were white or Asian, middle-aged with obesity class 1 and 2, which suggests that results may not be applicable to all patients with obesity. Furthermore, the maximum study duration was only 1 year and the study durations differed, which limits the scope for comparisons across weight loss medications.

\section{Conclusions and implication of key findings}

Significant weight loss and glycaemic improvement have been demonstrated in patients with T2DM treated with weight loss pharmacotherapy up to 1 year. However, in the absence of longer term clinical trials, real-world data will be required to assess the long-term effects on sustainability of weight loss, improvement in $\mathrm{HbA}_{1 \mathrm{c}}$ and cardiovascular outcomes. Further studies with larger groups of patients from black and minority ethnic backgrounds would surely be informative. When choosing pharmacotherapy for weight loss in patients with T2DM, several factors should be taken into account including co-morbidities, concomitant medications, expected weight loss, side effect tolerability and cost. Knowledge of weight-related and glycaemic effects of weight loss agents enable individualised regimens to be designed which may assist in obesity and diabetes management.

The approach for weight loss management should be a complications-centric model focused on preventing and ameliorating weight-related complications and not merely weight reduction.

Conflict of interest BM reports grants and personal fees from Novonordisk and personal fees from MSD, Jansen, Lilly, BI, Napp and Novonordisk outside the submitted work.

\section{Funding None.}

\section{References}

1. Eckel RH, Kahn SE, Ferrannini E, et al. Obesity and type 2 diabetes: what can be unified and what needs to be individualized? J Clin Endocrinol Metab 2011;96(6):1654-63. https://doi.org/10.1210/jc.2011-0585 
2. Cho NH, Shaw JE, Karuranga S, et al. IDF Diabetes Atlas: Global estimates of diabetes prevalence for 2017 and projections for 2045. Diabetes Res Clin Pract 2018;138:271-81. https://doi.org/10.1016/j.diabres.2018.02.023

3. Anderson JW, Kendall CWC, Jenkins DJA. Importance of weight management in type 2 diabetes: review with meta-analysis of clinical studies. J Am Coll Nutr 2003;22(5):331-9. https://doi.org/10.1080/ 07315724.2003 .10719316

4. Leitner DR, Frühbeck G, Yumuk V, et al. Obesity and type 2 diabetes: two diseases with a need for combined treatment strategies - EASO can lead the way. Obes Facts 2017;10(5):483-92. https://doi.org/ 10.1159/000480525

5. Matyjaszek-Matuszek B, Szafraniec A, Porada D. Pharmacotherapy of obesity — state of the art. Endokrynol Pol 2018;69(4):448-66. https://doi.org/10.5603/ep.2018.0048

6. Benaiges D, Pedro-Botet J, Flores-Le Roux JA, et al. Past, present and future of pharmacotherapy for obesity. Clinica e Investigacion en Arteriosclerosis 2017;29(6):256-64. https://doi.org/10.1016/j.artere.2017.06.003

7. Jadad AR, Moore RA, Carroll D, et al. Assessing the quality of reports of randomized clinical trials: is blinding necessary? Control Clin Trials 1996;17(1):1-2. https://doi.org/10.1016/0197-2456(95)00134-4

8. Berne C. A randomized study of orlistat in combination with a weight management programme in obese patients with type 2 diabetes treated with metformin. Diabet Med 2005;22(5):612-18. https://doi.org/ 10.1111/j.1464-5491.2004.01474.x

9. Kuo CS, Pei D, Yao CY, et al. Effect of orlistat in overweight poorly controlled Chinese female type 2 diabetic patients: a randomised, doubleblind, placebo-controlled study. Int J Clin Pract 2006;60(8):906-10. https://doi.org/10.1111/j.1742-1241.2006.01052.x

10. Derosa G, Cicero AFG, D'Angelo A, et al. Effects of 1-year orlistat treatment compared to placebo on insulin resistance parameters in patients with type 2 diabetes. J Clin Pharm Ther 2012;37(2):187-95. https://doi.org/10.1111/j.1365-2710.2011.01280.x

11. Guy-Grand B, Drouin P, Eschwège $E$, et al. Effects of orlistat on obesityrelated diseases: a six-month randomized trial. Diabetes Obes Metab 2004;6(5):375-83. https://doi.org/10.1111/j.1462-8902.2004.00359.x

12. Shi YF, Pan CY, Hill J, et al. Orlistat in the treatment of overweight or obese Chinese patients with newly diagnosed type 2 diabetes. Diabet Med 2005;22(12):1737-43. https://doi.org/10.1111/j.1464-5491.2005.01723.x

13. Davies MJ, Bergenstal R, Bode B, et al. Efficacy of liraglutide for weight loss among patients with type 2 diabetes: the SCALE diabetes randomized clinical trial. JAMA 2015;314(7):687-99. https://doi.org/10.1001/ jama.2015.9676

14. Garvey WT, Birkenfeld AL, Dicker D, et al. Efficacy and safety of liraglutide $3.0 \mathrm{mg}$ in individuals with overweight or obesity and type 2 diabetes treated with basal insulin: the SCALE insulin randomized controlled trial. Diabetes Care 2020;43(5):1085-93. https://doi.org/ $10.2337 / d c 19-1745$

15. Hollander P, Gupta AK, Plodkowski R, et al. Effects of naltrexone sustained-release/bupropion sustained-release combination therapy on body weight and glycemic parameters in overweight and obese patients with type 2 diabetes. Diabetes Care 2013;36(12):4022-9. https://doi.org/ 10.2337/dc13-0234

16. Gadde KM, Allison DB, Ryan DH, et al. Effects of low-dose, controlledrelease, phentermine plus topiramate combination on weight and associated comorbidities in overweight and obese adults (CONQUER): a randomised, placebo-controlled, phase 3 trial. Lancet 2011;377(9774): 1341-52. https://doi.org/10.1016/s0140-6736(11)60205-5

17. Apovian CM, Bergenstal RM, Cuddihy RM, et al. Effects of exenatide combined with lifestyle modification in patients with type 2 diabetes. Am J Med 2010;123(5):468.e9-17. https://doi.org/10.1016/j.amjmed. 2009.11.019

18. Bolinder J, Ljunggren Ö, Kullberg J, et al. Effects of dapagliflozin on body weight, total fat mass, and regional adipose tissue distribution in patients with type 2 diabetes mellitus with inadequate glycemic control on metformin. J Clin Endocrinol Metab 2012;97(3):1020-31. https://doi.org/ 10.1210/jc.2011-2260

19. Moon H-S, Matarese G, Brennan AM, et al. Efficacy of metreleptin in obese patients with type 2 diabetes: cellular and molecular pathways underlying leptin tolerance. Diabetes 2011;60(6):1647-56. https://doi.org/10.2337/db10-1791

20. Stenlöf K, Rössner S, Vercruysse F, et al. Topiramate in the treatment of obese subjects with drug-naive type 2 diabetes. Diabetes Obes Metab 2007;9(3):360-8. https://doi.org/10.1111/j.1463-1326.2006.00618.x

21. Toplak H, Hamann A, Moore R, et al. Efficacy and safety of topiramate in combination with metformin in the treatment of obese subjects with type 2 diabetes: a randomized, double-blind, placebo-controlled study. Int J Obes 2007;31(1):138-46. https://doi.org/10.1038/sj.ijo.0803382

22. Rosenstock J, Hollander P, Gadde KM, et al. A randomized, double-blind, placebo-controlled, multicenter study to assess the efficacy and safety of topiramate controlled release in the treatment of obese type 2 diabetic patients. Diabetes Care 2007;30(6):1480-6. https://doi.org/10.2337/dc062001

23. Goldstein DJ, Potvin JH, Hirsch J. Long-term weight loss: the effect of pharmacologic agents. Am J Clin Nutr 1994;60(5):647-57. https://doi.org/ 10.1093/ajcn/60.5.647

24. Norris SL, Zhang X, Avenell A, et al. Efficacy of pharmacotherapy for weight loss in adults with type 2 diabetes mellitus: a meta-analysis. Arch Intern Med 2004;164(13):1395-404. https://doi.org/10.1001/archinte.164.13.1395

25. Greenway FL, Fujioka K, Plodkowski RA, et al. Effect of naltrexone plus bupropion on weight loss in overweight and obese adults (COR-I): a multicentre, randomised, double-blind, placebo-controlled, phase 3 trial. Lancet 2010;376(9741):595-605. https://doi.org/10.1016/s0140-6736(10)608884

26. Apovian CM, Aronne L, Rubino D, et al. A randomized, phase 3 trial of naltrexone SR/bupropion SR on weight and obesity-related risk factors (COR-II). Obesity 2013;21:935-43. https://doi.org/10.1002/oby.20309

27. Pi-Sunyer $X$, Astrup A, Fujioka K, et al. A randomized, controlled trial of $3.0 \mathrm{mg}$ of liraglutide in weight management. N Engl J Med 2015; 373(1):11-22. https://doi.org/10.1056/nejmoa1411892

28. Perri MG, Sears SF, Clark JE. Strategies for improving maintenance of weight loss: toward a continuous care model of obesity management. Diabetes Care 1993;16(1):200-09. https://doi.org/10.2337/diacare.16.1.200

29. DeFronzo RA. Pharmacologic therapy for type 2 diabetes mellitus. Ann Intern Med 1999;131(4):281-303. https://doi.org/10.7326/0003-4819131-4-199908170-00008

30. Apovian CM, Okemah J, O'Neil PM. Body weight considerations in the management of type 2 diabetes. Advan Ther 2019;36(1):44-58. https://doi.org/10.1007/s12325-018-0824-8

31. Brown E, Wilding JPH, Barber TM, et al. Weight loss variability with SGLT2 inhibitors and GLP-1 receptor agonists in type 2 diabetes mellitus and obesity: mechanistic possibilities. Obes Rev 2019;20:816-28. https://doi.org/10.1111/obr.12841

32. Kushner RF, Calanna S, Davies M, et al. Semaglutide $2.4 \mathrm{mg}$ for the treatment of obesity: key elements of the STEP Trials 1 to 5. Obesity 2020; 28:1050-61. https://doi.org/10.1002/oby.22794

33. Damci T, Yalin S, Balci H, et al. Orlistat augments postprandial increases in glucagon-like peptide 1 in obese type 2 diabetic patients. Diabetes Care 2004;27(5):1077-80. https://doi.org/10.2337/diacare.27.5.1077

34. Marso SP, Daniels GH, Brown-Frandsen K, et al. Liraglutide and cardiovascular outcomes in type 2 diabetes. N Engl J Med 2016;375(4):31122. https://doi.org/10.1056/nejmoa1603827

35. Wiviott SD, Raz I, Bonaca MP, et al. Dapagliflozin and cardiovascular outcomes in type 2 diabetes. N Engl J Med 2019;380(4):347-57. https://doi.org/10.1056/nejmc1902837

36. Nissen SE, Wolski KE, Prcela L, et al. Effect of naltrexone-bupropion on major adverse cardiovascular events in overweight and obese patients with cardiovascular risk factors: a randomized clinical trial. JAMA 2016; 315(10):990-1004. https://doi.org/10.1001/jama.2016.1558 
Appendix 1. Protocol

\section{PHARMACOTHERAPY FOR WEIGHT LOSS IN ADULTS WITH TYPE 2 DIABETES - A SYSTEMATIC REVIEW OF RANDOMISED CONTROLLED TRIALS}

Not registered in Prospero

Claudia Coelho', Rachel Agius², James Crane', Barbara McGowan ${ }^{1,3}$

${ }^{1}$ Guy's and St Thomas' NHS Foundation Trust, London, United Kingdom

2 Diabetes and Endocrine Centre, Mater Dei Hospital, Msida, Malta

${ }^{3}$ King's College London - Diabetes and Nutritional Sciences, London, United Kingdom

\section{Review question}

For adults with type 2 diabetes, which medical treatments are available for weight loss, and does it result in significant weight loss when compared with placebo?

\section{Searches}

The search comprises keywords for the following concepts: T2DM, weight loss and pharmacotherapy. The databases will be searched from July 2004 to July 2020. English language filters will be applied.

MEDLINE via PubMed (NLM/NCBI)

Web of Science

EMBASE

Cochrane Central Register of Controlled Trials (CENTRAL) medRxiv

Supplemented with hand searches of reference lists and selected journals

\section{Types of study to be included}

Randomised controlled trials

Inclusion criteria: Medical treatments with the primary objective of weight loss, compared to placebo. Pharmacotherapy approved for obesity treatment per se and other agents investigated for weight loss. Weight loss strategies such as behavioural therapy could be used in conjunction with the intervention. No minimum length of follow-up time was established.

Exclusion criteria: Pharmacotherapy withdrawn from market due to safety concerns and non-regulated supplements.

\section{Condition or domain being studied \\ Obesity}

\section{Participants/population}

Adults with type 2 diabetes

Intervention(s), exposure(s)

Use of pharmacotherapy for the primary purpose of weight loss

\section{Comparator(s)/control}

Placebo

\section{Main outcome(s)}

a) Primary - Efficacy of Weight loss

Change from baseline in body weight $(\mathrm{kg}, \%)$

\section{Additional outcome(s)}

a). Secondary - Glycaemic control improvement

Change from baseline in $\mathrm{HbA} 1 \mathrm{c}(\%, \mathrm{mmol} / \mathrm{mol})$

b). Secondary - Efficacy of weight loss

Proportion of patients who achieved $>5 \%$ weight loss

\section{Data extraction (selection and coding)}

Titles and abstracts are reviewed for relevance by one author. If information in the abstracts is insufficient, 2 review authors will retrieve and assess potentially relevant full texts for inclusion. In cases of uncertainty, the other review author will be consulted, and consensus attained. For all included studies, one review author will extract the data using a standardized template (excel) and a second author verify the extracted data for accuracy. Mean values of change from baseline in weight and $\mathrm{HbA} 1 \mathrm{c}$ during follow-up are extracted at the end of the intervention. All data reported as absolute values during follow-up will be converted to change from baseline in unit percent by dividing by the baseline weight. Authors of individual studies may be contacted for clarification.

Risk of bias (quality) assessment

Jadad score used at outcome and study level

\section{Strategy for data synthesis}

We will provide narrative synthesis of the findings from included studies. We will present the studies by drug name and summarize findings pertinent to weight loss and glycaemic control. We will not provide detailed summaries of their statistical findings but instead comment more broadly on study design characteristics and outcome measurements and how these may impact clinical use.

\section{Analysis of subgroups or subsets}

Not provided.

\section{Contact details for further information}

Author for correspondence -

Prof Barbara McGowan Barbara.mcgowan@gstt.nhs.uk

Type and method of review

Systematic review

Anticipated or actual start date

May 2020

\section{Anticipated completion date}

September 2020

\section{Funding sources/sponsors}

None specified.

\section{Conflicts of interest}

None specified.

None known

\section{Language}

English

\section{Country}

United Kingdom

\section{Stage of review}

Review completed September 2020 